\title{
The comparative importance of species traits and introduction characteristics in tropical plant invasions
}

\author{
Wayne Dawson $^{1,2 \star}$, David F. R. P. Burslem ${ }^{1}$ and Philip E. Hulme ${ }^{3}$
}

'Institute of Biological and Environmental Sciences, University of Aberdeen, Cruickshank Building, Aberdeen, AB24 3UU, UK, ${ }^{2}$ Centre for Ecology and Hydrology, Penicuik, Midlothian EH26 OQB, UK, ${ }^{3}$ The Bio Protection Research Centre, PO Box 84, Lincoln University, Canterbury, New Zealand
${ }^{*}$ Correspondence: Wayne Dawson, Ecology, Department of Biology, University of Konstanz, Universitaetsstrasse 10, D 78464 Konstanz, Germany.

E mail: wayne.dawson@uni konstanz.de

\begin{abstract}
Aim We used alien plant species introduced to a botanic garden to investigate the relative importance of species traits (leaf traits, dispersal syndrome) and introduction characteristics (propagule pressure, residence time and distance to forest) in explaining establishment success in surrounding tropical forest. We also used invasion scores from a weed risk assessment protocol as an independent measure of invasion risk and assessed differences in variables between high and low risk species.
\end{abstract}

Location East Usambara mountains, Tanzania.

Methods Forest transect surveys identified species establishing in disturbed and intact forest. Leaf traits (specific leaf area and foliar nutrient concentrations) were measured from leaves sampled in high light environments.

Results A leaf traits spectrum was apparent, but species succeeding or failing to establish in either disturbed or intact forest were not located in different parts of the spectrum. Species with high invasion risk did not differ in their location on the leaf trait spectrum compared with low risk species but were more likely to be bird/primate dispersed. For 15 species establishing in forest quadrats, median canopy cover of quadrats where seedlings were present was correlated with a species value along the leaf trait spectrum. Species establishing in disturbed forest were planted in twice as many plantations and were marginally more likely to be bird or primate dispersed than species failing to become established in disturbed forest. Establishment in intact forest was more likely for species planted closer to forest edges.

Main conclusions Leaf and dispersal traits appear less important in the colonization of tropical forest than introduction characteristics. It appears, given sufficient propagule pressure or proximity to forest, alien species are much more likely to establish independently of leaf traits or dispersal syndrome in continental tropical forests.

\section{Keywords}

Biological invasion, East Africa, exotics, introduction effort, life history, rain forest.

\section{INTRODUCTION}

While many plant attributes may contribute to the establish ment success of alien plants (Pyšek \& Richardson, 2007), an emerging synthesis points to the importance of leaf traits and dispersal syndrome (Rejmánek et al., 2005; Richardson \& Pyšek, 2006). High foliar nutrient concentrations ( $N$ and $P$ ) and greater specific leaf area (SLA) lead to a faster rate of return on nutrient and dry weight investment in leaves and greater photosynthetic assimilation rate, which result in faster relative growth rates (Reich et al., 1998; Grotkopp et al., 2002; Wright et al., 2004; Santiago \& Wright, 2007). Invasive alien plants have been found to have greater SLA and leaf nutrient concentrations than co occurring native species (Baruch \& Goldstein, 1999; Dietz et al., 2004; Leishman et al., 2007; Penuelas et al., 2010), and alien species perceived as more 
invasive have been found to have a greater SLA than less invasive species (Grotkopp et al., 2002; Hamilton et al., 2005; Grotkopp \& Rejmánek, 2007). These leaf traits result in faster relative growth rates that are expected to facilitate the establishment of invasive alien plants in native vegetation (Rejmánek et al., 2005). However, traits at the 'fast' end of the leaf trait continuum may only be of importance in colonizing habitats where light is not limiting and may be of less importance for establishment in the understorey of forests (Wright et al., 2004). Traits relating to effective seed dispersal are also often associated with invasion success (Rejmánek \& Richardson, 1996; Hamilton et al., 2005; Lloret et al., 2005; Buckley et al., 2006). Seed dispersal of fleshy fruited species by frugivorous birds and mammals has been recognized as an important factor allowing invasion of less disturbed habitats (Milton et al., 2007) and may be an important mode of alien plant dispersal in tropical forests with high frugivore diversity (Cordeiro et al., 2004; Gosper \& Vivian Smith, 2009). Small seed size is cited as an important trait of successful invaders through increasing the dispersal distance of species and concomitantly greater reproductive output (Rejmánek \& Richardson, 1996; Hamilton et al., 2005). However, in addi tion to these species traits, an increasing body of evidence suggests that introduction effort and/or residence time may be of overriding importance in biological invasion and modify or mask the role of species traits (Wilson et al., 2007; Simberloff, 2009). Greater introduction effort is likely to have a positive effect on the probability that a species will survive demo graphic and environmental stochasticity (Lockwood et al., 2005), and positive relationships between alien species estab lishment and introduction effort have been found both across (Krivanek et al., 2006; Lambdon et al., 2008a) and within species (Edward et al., 2009). In addition, it is generally understood that the probability of naturalization (Dawson et al., 2009a), regional distribution (Williamson et al., 2009) and rate of range increase (Hulme, 2011a) are greater for species introduced earlier than for those introduced more recently.

These findings suggest that to be successful invaders, alien plants need to be introduced in sufficient numbers to avoid stochastic extinctions of small populations, possess leaf traits that enable them to establish in native vegetation and be able to disperse over long distances. However, no study to date has contrasted the relative importance of species traits (e.g. leaf traits, dispersal syndrome) and introduction characteristics (e.g. propagule pressure, residence time) in the successful establishment of alien species in semi natural and natural habitats. Moreover, objective measures of alien species success are not used consistently in studies of biological invasions, but such measures are required to elucidate the ecological rather than anthropogenic drivers behind invasions (Hulme, 2011b).

To address these issues, we examined the extent to which leaf traits, propagule pressure, seed size and dispersal syn drome explained differences in the establishment of alien plant species spreading from Amani Botanical Garden (ABG) into neighbouring rain forest in the East Usambara Mountains of
Tanzania, based on detailed field surveys (Dawson et al., 2008). Our field surveys gave us two objective measures of local species establishment success, namely the ability of species to establish in disturbed forest and the ability of species to establish in intact forest. Historical records of plantings made at $A B G$ allowed us to account for the effect of residence time and introduction effort on differences in establishment success among species. In addition, we analysed the relationship between variables and invasion risk, obtained from the Australian weed risk assessment (WRA; Pheloung et al., 1999), which represents a regionally non specific, objective measure of plant species invasiveness. Finally, the leaf traits associated with successful establishment in forest may be dependent upon small scale habitat conditions such as light availability (Poorter \& Bongers, 2006). We therefore assessed the relationship between leaf traits in a high light environment and canopy cover for forest quadrats where seedlings and saplings of species occurred.

\section{METHODS}

\section{Study site}

The ABG $\left(5^{\circ} 05^{\prime} 30^{\prime} \mathrm{S}, 38^{\circ} 38^{\prime} 10^{\prime \prime} \mathrm{E}\right)$ is a 300 hectare botanic garden situated in the lowland $(400700 \mathrm{~m})$ and submontane (above $700 \mathrm{~m}$ ) rain forests of Amani Nature Reserve in the East Usambara Mountains in north east Tanzania. The entire site straddles an altitudinal range of $4001050 \mathrm{~m}$ and has a tropical monsoonal climate with average annual rainfall of $2000 \mathrm{~mm}$. The ABG plantations were established in submontane and lowland rain forest and are contiguous with forest edges in a number of locations. The ABG is now largely overgrown with colonizing native and alien tree species. More than 500 species (mostly woody) were planted over a 28 year period from 1902 to 1930 in a series of trial plantations (P.J. Greenway, unpublished data; Dawson et al., 2008).

\section{Forest establishment and invasion risk}

To generate an objective measure of forest establishment, systematic surveys of alien plants found in the forest bordering former plantations were conducted in 2008. The presence of alien seedlings, saplings and adults was recorded along 30 transects, each $10 \mathrm{~m}$ wide and running $250 \mathrm{~m}$ perpendicular to the forest edge. Rectangular quadrats were established every $25 \mathrm{~m}$ along each transect, measuring $10 \mathrm{~m}$ by $5 \mathrm{~m}$. On most transects, the forest surveyed was semi natural or natural beyond $150 \mathrm{~m}$ from the edge, with late successional tree species present at high density, and minimal signs of human disturbance (e.g. fire, tracks, evidence of pole cutting); forest nearer to edges was often highly disturbed or secondary, with evidence of clear felling in the past. Based on the results of previous studies (Dawson et al., 2008, 2009a), we focused on 39 species ( 29 trees, four palms, five shrubs and one liana) that differed in the degree to which they colonized tropical forest, and the majority $(n=36)$ were known to have at least 
naturalized in $\mathrm{ABG}$, i.e. the species had recruited new adults into the population (Table 1). The first local measure of invasion success scored species as successful if adult individuals or saplings $>1 \mathrm{~m}$ tall were found in quadrats in disturbed edge forest, $<150 \mathrm{~m}$ from edges $(n=20)$. The second local response variable scored species as successful only if they were present in quadrats in intact forest (at least $150 \mathrm{~m}$ from forest edges, $n=11$ ). These categories were not mutually exclusive because all species capable of establishing in intact forest were also found in disturbed forest. These two distinct measures of establishment success were used as it was assumed a stronger set of environmental filters would limit invasion of less disturbed forest. The transition between disturbed and intact forest may represent a filter, through which only a subset of species establishing in forest with certain traits can pass. Alternatively, the different composition of alien species colo nizing in the two forest types may simply reflect a distance barrier that could be overcome by sufficient propagule pressure

Table 1 The 39 species used in this study, including life forms and whether or not each species was found establishing in disturbed or intact forest. Also shown are WRA outcomes (from Dawson et al., 2009b), with species judged as having a high or low invasion risk.

\begin{tabular}{|c|c|c|c|c|c|}
\hline Species & Family & Life form & Forest & Intact forest & WRA score \\
\hline Mangifera indica $\mathrm{L}$. & Anacardiaceae & Tree & No & No & Low \\
\hline Ilex paraguariensis A. St. Hil. & Aquifoliaceae & Tree & No & No & Low \\
\hline Areca catechu $\mathrm{L}$. & Arecaceae & Palm & No & No & Low \\
\hline Arenga pinnata (Wurmb) Merr. & Arecaceae & Palm & Yes & Yes & Low \\
\hline Elaeis guineensis Jacq. & Arecaceae & Palm & Yes & Yes & High \\
\hline Livistona chinensis (Jacq.) R. Br. Ex Mart. & Arecaceae & Palm & Yes & Yes & Low \\
\hline Spathodea campanulata P. Beauv. & Bignoniaceae & Tree & Yes & Yes & High \\
\hline Cordia alliodora (Ruiz \& Pav.) Oken & Boraginaceae & Tree & Yes & No & High \\
\hline Hevea brasiliensis (Willd. Ex. A. Juss) Mull. Arg. & Euphorbiaceae & Tree & No & No & Low \\
\hline Hura crepitans $\mathrm{L}$. & Euphorbiaceae & Tree & No & No & Low \\
\hline Manihot glaziovii Mull. Arg. & Euphorbiaceae & Tree & No & No & Low \\
\hline Myroxylon peruiferum L. f.* & Fabaceae & Tree & No & No & Low \\
\hline Senna multijuga (Rich.) H.S. Irwin \& Barneby & Fabaceae & Tree & No & No & Low \\
\hline Hydnocarpus pentandrus (Buch. Ham.) Oken* & Salicaceae & Tree & No & No & Low \\
\hline Cinnamomum camphora (L.) J. Presl & Lauraceae & Tree & Yes & No & High \\
\hline Cinnamomum verum J. Presl & Lauraceae & Tree & Yes & Yes & High \\
\hline Cola nitida (Vent.) Schott \& Endl. & Malvaceae & Tree & No & No & Low \\
\hline Clidemia hirta (L.) D. Don $\dagger$ & Melastomataceae & Shrub & Yes & Yes & High \\
\hline Cedrela odorata $\mathrm{L}$. & Meliaceae & Tree & Yes & Yes & High \\
\hline Toona ciliata M. Roem. & Meliaceae & Tree & Yes & No & Low \\
\hline Artocarpus heterophyllus Lam. & Moraceae & Tree & Yes & No & Low \\
\hline Castilla elastica Sesse & Moraceae & Tree & Yes & Yes & High \\
\hline Pimenta racemosa (Mill.) J.W. Moore ${ }^{*}$ & Myrtaceae & Tree & No & No & Low \\
\hline Psidium cattleianum Sabine & Myrtaceae & Tree & Yes & No & High \\
\hline Psidium guajava L. & Myrtaceae & Tree & Yes & No & High \\
\hline Syzygium jambos (L.) Alston & Myrtaceae & Tree & Yes & Yes & High \\
\hline Syzygium malaccense (L.) Merr. \& L.M. Perry* & Myrtaceae & Tree & No & No & Low \\
\hline Piper aduncum L. & Piperaceae & Tree & Yes & Yes & High \\
\hline Piper nigrum $\mathrm{L}$. & Piperaceae & Liana & Yes & Yes & Low \\
\hline Hovenia dulcis Thunb. & Rhamnaceae & Tree & Yes & No & High \\
\hline Maesopsis eminii Engl. $\dagger$ & Rhamnaceae & Tree & Yes & Yes & Low \\
\hline Rubus ellipticus Sm. & Rosaceae & Shrub & No & No & High \\
\hline Rubus rosifolius $\mathrm{Sm}$. & Rosaceae & Shrub & Yes & No & High \\
\hline Cinchona pubescens Vahl & Rubiaceae & Tree & No & No & High \\
\hline Coffea canephora Pierre ex A. Froehner & Rubiaceae & Tree & Yes & Yes & Low \\
\hline Acer oblongum Wall. Ex DC. & Sapindaceae & Tree & No & No & Low \\
\hline Camellia sinensis (L.) Kuntze & Theaceae & Tree & Yes & No & Low \\
\hline Duranta erecta $\mathrm{L}$. & Verbenaceae & Shrub & No & No & High \\
\hline Lantana camara L. $\dagger$ & Verbenaceae & Shrub & Yes & No & High \\
\hline
\end{tabular}

WRA, weed risk assessment.

Data pertaining to species traits, introduction history and canopy cover in occupied quadrats are given in Table S1.

${ }^{*}$ Species that had not naturalized (i.e. no new adult individuals were found), but vigorous saplings and small trees were known (Dawson et al., 2008). †Species that were found in forest surveys, but which had no data on planting history and were excluded from analyses investigating forest establishment success. 
and dispersal. Canopy cover was measured in the centre of each quadrat along the transects in four different directions with a spherical densiometer (Lemmon, 1956), and a mean quadrat canopy cover was calculated.

The number of plantations originally established per species within ABG was obtained from historical surveys (P.J. Greenway, unpublished data) as a measure of propagule pressure for 36 species; the remaining three species had unclear or unknown planting histories (see Table S1 in Supporting Information). These species were excluded from analyses of forest establishment but used to examine the importance of canopy cover on leaf traits. Because distance from a plantation will modify any effect of propagule pressure (Edward et al., 2009), the distance between the nearest plantation and a forest edge for each species was estimated and used as a variable in subsequent analyses. We were also able to extract first introduction dates (year) from historical surveys for all 36 species. The majority of species $(n=30)$ were planted within a 10 year period between 1902 and 1911. The remaining six species were planted in 1930 (Table 1).

In addition to the field based response variables, we also obtained independent scores of invasion risk from the Australian WRA protocol (Pheloung et al., 1999), adapted for the tropics and applied to extant alien plant species at ABG (Dawson et al., 2009b). These scores are calculated from answers to 49 questions regarding species biology, ecology, reproduction, introduction and invasion history, biogeography and climate requirements (Pheloung et al., 1999). The WRA protocol has predicted invasion risk of alien plant species in retrospective tests across multiple geographical regions (Gor don et al., 2008), with species obtaining a score above 6 considered high risk, those between 1 and 6 of moderate risk and scores below 1 indicate low risk. Following the method of Gordon et al. (2008), we grouped species with scores below 6 together as non invasive species $(n=20)$ and kept species with scores above 6 as high risk, invasive species $(n=16)$. This independent measure of invasion risk allowed us to assess the relationship between likelihood of invasion and leaf traits, as well as establishing whether or not propagule pressure was greater for high risk than for low risk species.

\section{Trait quantification}

Specific leaf area was measured from leaves collected in ABG from 5 to 10 individual plants per species in May 2007. Fully expanded leaves close to apical meristems and with minimal or no damage were sampled from individuals exposed to as much light as possible. As such, individuals growing along paths, in large canopy openings, on open land, and along plantation and forest edges were targeted for leaf collection. Because of height constraints, saplings of taller tree species were usually sampled, but for smaller trees and shrubs (e.g. Clidemia hirta, Lantana camara, Duranta erecta and Syzygium jambos), adults were also sampled. The number of leaves collected per individual varied from two to six among species depending on leaf size. Leaf area was measured as soon as possible after collection using a flatbed scanner $(4800 \times 9600 \mathrm{dpi})$ and the digital image analysis program ImageJ (Rasband, 2007). Following standard protocols (Cornelissen et al., 2003), measurement of area included leaf petiole and rachis material, except for palm species, for which a random subsample of three pinnules or lamina sections (including base and midrib) were collected per frond. Leaves were partially air dried in an electric oven for $2 \mathrm{~h}$ and were stored in silica gel before being placed in a drying oven at $60^{\circ} \mathrm{C}$ for $72 \mathrm{~h}$. Leaves were bulked per individual plant on weighing, to obtain dry weights and calculate SLA per individual.

Nutrient analyses were conducted on one dried and milled leaf sample (excluding petiole and rachis material) per individual from five individuals per species. Ground samples were then subjected to an $\mathrm{HCl} / \mathrm{H}_{2} \mathrm{SO}_{4}$ acid digest procedure (Allen et al., 1989) and analysed for $\mathrm{N}$ and $\mathrm{P}$ colorimetrically (Foss Flow Injection Analyser model 5010, Foss, Hillerød, Denmark), for $\mathrm{Mg}$ and $\mathrm{Ca}$ using atomic absorption spectro photometry (Perkin Elmer Analyst 100, Perkin Elmer, Waltham, Massachusetts, USA) and for K by flame emission spectrophotometry (Perkin Elmer Analyst 100, emission mode). Average nutrient concentrations $\left(\mathrm{mg} \mathrm{g}^{-1}\right.$ dry weight of leaf) and SLA ( $\mathrm{cm}^{2} \mathrm{~g}^{-1}$ dry weight of leaf) were calculated per species. We obtained a binary dispersal variable which consisted of scoring a species if there was evidence of dispersal by birds and/or primates in any part of a species native or introduced range. The dispersal syndrome of species not included in the bird/primate grouping was heterogeneous, but we were primarily interested in the importance of bird/primate dispersal, given the abundance of arboreal frugivores in this tropical forest context. Data on dispersal syndrome were largely obtained from peer reviewed literature and databases (see Table S1). Finally, seed size data were recorded as dry weight mass in milligram and were largely obtained from the Seed Information Database of the Royal Botanic Gardens, Kew (2008), but other peer reviewed primary literature sources were also used.

\section{Statistical analysis}

Measures for SLA and the foliar nutrient concentrations (natural log transformed) were subjected to principal compo nents analysis (PCA) in order to capture the leaf traits spectrum. Following the method of Wright et al. (2004), only the first axis that explained the greatest proportion of total variation was extracted, and the species' scores along this axis were used as a proxy for species position along the leaf trait economics spectrum. This axis was included as an explanatory variable in subsequent analysis.

Analysis of the two local forest establishment measures consisted of generalized linear models (GLM) with a Bernoulli error distribution. Although it was possible to derive a continuous variable for the local measures of establishment success, data violated assumptions of homogeneity of variance and normality of residuals and had strongly influential data points. For this reason, these measures were scored as binary 
variables. The leaf trait PCA axis, bird/primate dispersal, seed size, introduction date and the two measures of propagule pressure (distance to a forest edge and number of plantations planted) were explanatory variables. Backwards model selec tion was used to find a minimum adequate model, by removing variables individually and applying likelihood ratio tests. Invasion risk according to WRA scores was also analysed using a GLM with Bernoulli error distribution and with the same explanatory variables, comparing species with a high invasion risk (a score $>6$ ) with a low invasion risk species (a score $\leq 6$ ). Although WRA generates a continuous variable, users and developers have been explicit in stating that WRA scores should not be used as a continuous measure of invasion success but rather as a binary variable that better reflects the ultimate outcome and application of a WRA analysis to accept or reject a species as low or high invasion risk (Gordon et al., 2008). To check whether individual leaf traits (rather than a spectrum) might be important in relation to species success, we fitted the aforementioned models and conducted model selection again for each individual leaf trait (SLA and concentrations of each foliar nutrient) separately. Using the canopy cover data per plot from the transects, we checked for differences in percentage canopy cover between intact and disturbed forest types using a non parametric Mann Whitney $U$ test.

We also examined the relationship between leaf traits and the light environment within which seedlings and saplings of species were establishing in forest. We did this by calculating the median canopy cover in forest quadrats occupied by seedlings and saplings for each species occurring in more than one quadrat $(n=15)$. We then analysed the relationship between canopy cover and the PCA leaf trait axis, and also individual leaf traits, using Pearson's product moment corre lation. The analysis also included the shrub species $L$. camara and C. hirta (adult plants as well as seedlings and saplings) and the pioneer tree Maesopsis eminii. All analyses were performed in the program $\mathrm{R}$ version 2.10.1 ( $\mathrm{R}$ Development Core Team, 2009).

\section{RESULTS}

\section{Leaf traits spectrum}

The first axis from the PCA of all six leaf traits explained more than half of the total variation among the 39 species, with all traits covarying positively with one another, and significantly so for SLA, $\mathrm{N}, \mathrm{P}, \mathrm{K}$ and $\mathrm{Mg}$ (Table 2). This axis defined the leaf traits spectrum and was used as an explanatory variable in subsequent analyses.

\section{Forest establishment and invasion risk}

Differences in individual leaf trait values between species succeeding and failing to establish in disturbed forest were largely non significant (Table 3). Species that established successfully in intact forest had a higher mean foliar $\mathrm{K}$
Table 2 Results of principal components analysis of and Pear son's product moment correlation coefficients between SLA and foliar nutrient concentrations for 39 alien plant species in Amani Botanical Garden. Percentage of total variation explained by the first principal component axis, and loadings of each trait on the axis are shown. The negative loadings indicate that each trait is negatively correlated with the axis but are positively correlated with one another.

\begin{tabular}{|c|c|c|c|c|c|c|}
\hline \multirow{2}{*}{\multicolumn{2}{|c|}{$\begin{array}{l}\begin{array}{l}\text { Principle } \\
\text { component axis } 1\end{array} \\
\text { Variation } \\
\text { explained }=53 \%\end{array}$}} & \multicolumn{5}{|c|}{ Correlation co efficients } \\
\hline & & \multicolumn{5}{|l|}{ Trait } \\
\hline Trait & Loadings & $\mathrm{N}$ & $\mathrm{P}$ & $\mathrm{K}$ & $\mathrm{Mg}$ & $\mathrm{Ca}$ \\
\hline SLA & 0.84 & $0.74^{* * *}$ & $0.67^{* * *}$ & $0.44^{* * *}$ & $0.39^{*}$ & 0.20 \\
\hline $\mathrm{N}$ & 0.92 & & $0.77^{* * *}$ & $0.37^{*}$ & $0.50^{* *}$ & $0.45^{* *}$ \\
\hline $\mathrm{P}$ & 0.85 & & & $0.43^{* *}$ & $0.31^{*}$ & $0.35^{*}$ \\
\hline $\mathrm{K}$ & 0.57 & & & & 0.23 & 0.07 \\
\hline $\mathrm{Mg}$ & 0.59 & & & & & 0.23 \\
\hline $\mathrm{Ca}$ & 0.48 & & & & & \\
\hline
\end{tabular}

Significance of correlation coefficients are denoted by: ${ }^{*} P \leq 0.05$, ${ }^{* *} P \leq 0.01,{ }^{* *} P \leq 0.001$. SLA and nutrient concentrations were all natural $\log$ transformed prior to analysis.

Table 3 Means of foliar nutrient concentrations and SLA for species either failing or succeeding to establish in disturbed and intact forest, and that are judged to be of high or low invasion risk according to WRA.

\begin{tabular}{|c|c|c|c|c|c|c|}
\hline & \multicolumn{2}{|c|}{$\begin{array}{l}\text { Establishing in } \\
\text { disturbed forest }\end{array}$} & \multicolumn{2}{|c|}{$\begin{array}{l}\text { Establishing in } \\
\text { intact forest }\end{array}$} & \multicolumn{2}{|c|}{$\begin{array}{l}\text { WRA invasion } \\
\text { risk }\end{array}$} \\
\hline & Failure & Success & Failure & Success & Failure & Success \\
\hline $\mathrm{N}\left(\mathrm{mg} \mathrm{g}^{-1}\right)$ & 24.83 & 24.53 & 25.60 & 22.55 & 24.49 & 24.88 \\
\hline $\mathrm{P}\left(\mathrm{mg} \mathrm{g}^{-1}\right)$ & 1.76 & 1.67 & 1.76 & 1.58 & 0.89 & 1.69 \\
\hline $\mathrm{K}\left(\mathrm{mg} \mathrm{g}^{-1}\right)$ & 25.18 & 14.26 & 12.22 & 33.92 & 28.44 & 26.05 \\
\hline SLA $\left(\mathrm{cm}^{2} \mathrm{~g}^{-1}\right)$ & 243.24 & 200.911 & 228.54 & 199.69 & 222.82 & 215.85 \\
\hline $\mathrm{Mg}\left(\mathrm{mg} \mathrm{g}^{-1}\right)$ & 4.70 & 4.32 & 4.79 & 3.80 & 4.33 & 4.68 \\
\hline $\mathrm{Ca}\left(\mathrm{mg} \mathrm{g}^{-1}\right)$ & 12.48 & 18.06 & 15.60 & 15.54 & 12.79 & 19.07 \\
\hline
\end{tabular}

SLA, specific leaf area, WRA, weed risk assessment.

Note that only foliar $\mathrm{K}$ concentrations differed marginally $(P=0.09)$ between species failing and succeeding to establish in intact forest; all other comparisons of successful and unsuccessful/high risk and low risk species were not significant in binomial generalized linear models.

concentration than unsuccessful species, but this difference was not significant at the $5 \%$ level $(P=0.09$, Table 3$)$. There was no significant relationship between the PCA leaf trait axis or introduction date and the ability of species to establish in surrounding forest, whether disturbed or intact (Table 4). After model selection, only planting effort and dispersal syndrome remained as significant variables (Fig. 1). Species establishing in disturbed forest were planted in a greater number of plantations than unsuccessful species $(8.9 \pm 1.2$ vs. $4.6 \pm 0.95$; Table 4; Fig. 1). Species dispersed by birds and 
Table 4 Parameter estimates and standard errors (in parentheses) from initial (regular font) and minimum adequate models (bold font) analysing successful establishment of 36 alien plant species from Amani Botanical Garden in disturbed and intact forest and invasion risk according to WRA scores.

\begin{tabular}{ccll}
\hline & $\begin{array}{l}\text { Establishing in } \\
\text { disturbed forest }\end{array}$ & $\begin{array}{l}\text { Establishing } \\
\text { in intact forest }\end{array}$ & $\begin{array}{l}\text { WRA invasion } \\
\text { risk }\end{array}$ \\
\hline $\begin{array}{c}\text { Number of } \\
\text { plantations }\end{array}$ & $0.992(0.584)^{* *}$ & $0.080(0.521)$ & $0.567(0.531)$ \\
$\begin{array}{c}\text { Distance to } \\
\text { forest edge, } m\end{array}$ & $0.449(0.602)$ & $2.033(1.051)^{* *}$ & $0.146(0.641)$ \\
$\begin{array}{c}\text { Introduction } \\
\text { date, year }\end{array}$ & $0.271(0.676)$ & $0.813(0.817)$ & $0.395(0.742)$ \\
$\begin{array}{c}\text { Seed mass } \\
\text { (mg) }\end{array}$ & $0.768(0.793)$ & $0.836(0.770)$ & $1.542(0.863)^{* *}$ \\
$\begin{array}{c}\text { Bird/primate } \\
\text { dispersal }\end{array}$ & $0.862(0.688)$ & $1.397(0.864)$ & $0.207(0.687)$ \\
Other & $1.027(0.562)^{* *}$ & & $\mathbf{0 . 4 7 3 ( 0 . 5 3 0 )}$ \\
dispersal & $0.164(0.752)$ & $1.408(0.850)^{* *}$ & $1.173(0.882)$ \\
Leaf trait & $0.418(\mathbf{0 . 5 5 8})$ & & $1.234(0.655)^{* *}$ \\
$\begin{array}{c}\text { PC axis } \\
R^{2}(\%)\end{array}$ & $40.8 / 33.5$ & $36.6 / 27.4$ & $46.5 / 41.1$
\end{tabular}

WRA, weed risk assessment

Nagelkerke's $R^{2}$ is also given for full (regular) and minimum (bold) models. Parameter estimates shown were fitted in models without an intercept, and all continuous variables were centred and scaled to their means and standard deviations.

Significant estimates are indicated by: ${ }^{*} P<0.1,{ }^{*} P \leq 0.05$.

primates were marginally more likely to have established in disturbed forest than species with other methods of dispersal (Table 4; Fig. 1). Of the species establishing in disturbed forest,
$70 \%$ were dispersed by birds or primates, compared to $31 \%$ of species failing to establish. The predicted probability of establishment in disturbed forest for species planted in only one plantation was under $20 \%$ if not dispersed either by birds or by primates (Fig. la) but rose to nearly $50 \%$ if these dispersal syndromes were present (Fig. 1b). When leaf traits were considered individually in models, none were significantly associated with establishment in disturbed forest (see Table S2), but when SLA or foliar N were included, only the number of plots planted remained in the minimum model after model selection, with species planted in a greater number of plots more likely to establish (estimate $=0.95$, SEM $= \pm 0.42, z=2.30, P=0.02$ ).

Distance of planting site from forest edges was the only factor retained in minimum adequate models of successful establishment of species in intact forest (Table 4). Eighty two per cent of species establishing in intact forest had been planted $<200 \mathrm{~m}$ from a forest edge (Table 3, Fig. 2a). The predicted probability of establishment in primary forest was almost $60 \%$ for species planted only $50 \mathrm{~m}$ away from forest edges, whilst no species planted $>400 \mathrm{~m}$ away managed to establish in primary forest (Fig. 2). When the leaf traits spectrum was replaced by individual leaf traits, both distance from forest edges and foliar $\mathrm{K}$ concentrations were retained in a minimum model (parameter estimates from binomial GLM intercept $=-1.747( \pm 0.755), P=0.02$; distance $=$ $-2.41( \pm 1.13), \quad P=0.03 ; \quad \log$ foliar $K=1.22( \pm 0.57)$, $P=0.03$; Nagelkerke's $\left.R^{2}=0.459\right)$. Species with higher foliar $\mathrm{K}$ concentrations had a higher probability of successful establishment in intact forest (Fig. 2b), and species planted closer to forest edges continued to have a higher likelihood of establishment (Fig. 2a). However, the other individual nutrient concentrations and SLA were not related to intact forest establishment when considered alone (Table 3 ) or with other
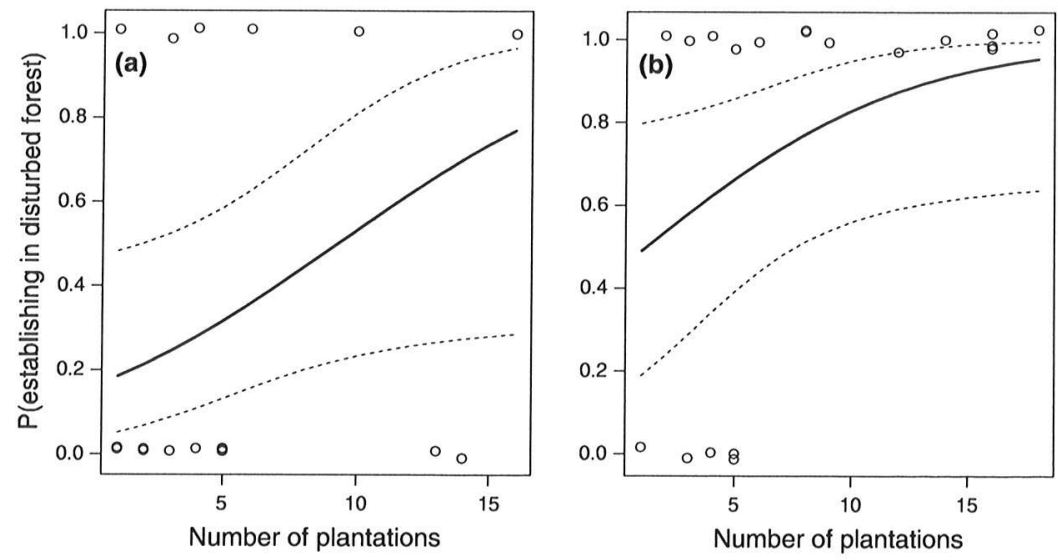

Figure 1 The probability of establishing in disturbed forest for (a) species not dispersed by birds or primates and (b) species that are bird/ primate dispersed, in relation to the number of plantations established per species. Bold lines represent predicted probability of forest establishment according to minimum adequate model. Dashed lines represent $95 \%$ confidence envelope of fitted line. Dots represent actual data points. (NB. Some data points may be hidden owing to multiple species with the same establishment outcome and number of plantations planted.) 

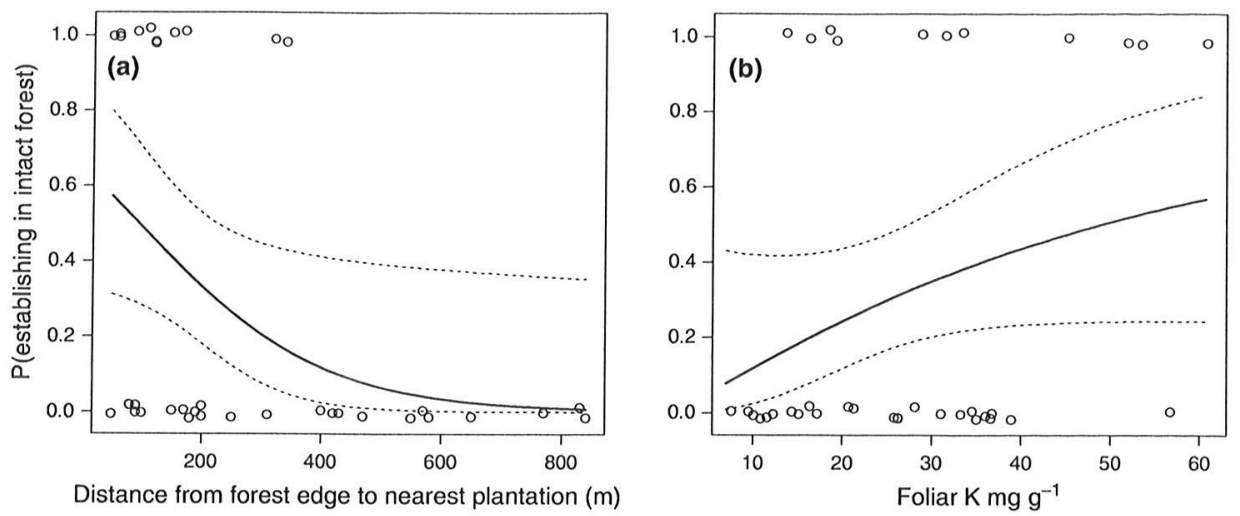

Figure 2 The relationship between probability of establishment in intact forest, and (a) the minimum distance between a forest edge and nearest plantation and (b) foliar K concentrations for 36 species introduced to Amani Botanical Garden. Dots represent actual data points. Solid line represents predicted probability of establishment according to fitted model; dashed lines are $95 \%$ confidence envelope of fitted line.

variables (Table S2). Canopy cover of intact forest plots differed significantly from plots in disturbed forest $(W=7647, P<0.001)$. However, the absolute difference in canopy cover was small, with a median cover of $91.1 \%$ for disturbed forest plots and $93.3 \%$ for intact forest plots.

Leaf trait PCA axis scores did not differ significantly between high risk invasive species and low risk non invasive species, as judged by the WRA. Dispersal and seed mass were retained in the minimum model, as bird/primate dispersed species were more likely to have a high invasion risk and smaller seeded species had a higher risk than larger seeded species (Table 3). Bird/primate dispersed species represented $75 \%$ of high risk species, compared to $35 \%$ of low risk species. When individual leaf traits were included instead of the leaf trait axis, none were related significantly to invasion risk (Table 3 , Table S2), but only seed mass remained in the minimum model after model selection when foliar $\mathrm{K}$ was included (estimate $=-1.15$, SEM $= \pm 0.44, P=0.01$ ). For 15 species with seedlings and saplings present in more than one forest quadrat, the median canopy cover of occupied quadrats was significantly positively correlated with the leaf trait PCA axis (Fig. 3a) and signifi cantly negatively correlated with foliar $\mathrm{N}$ and $\mathrm{P}$ concentrations (Fig. 3b,c). The negative correlation between SLA and median canopy cover was not significant (Fig. 3d). The correlations between foliar $\mathrm{Mg}$ and $\mathrm{Ca}$ and canopy cover were also not significant $(\mathrm{Mg} \quad$ Pearson's $R=-0.15, \quad P=0.60 ; \quad \mathrm{Ca}$ Pearson's $R=-0.42, P=0.12$ ). The correlation between foliar $\mathrm{K}$ concentration and median canopy cover was not significant (Pearson's $R=-0.50, P=0.06$ ).

\section{DISCUSSION}

Introduction characteristics, and not species traits, appeared to be of primary importance for the successful establishment in disturbed or intact forest at Amani. In contrast, leaf traits were relatively unimportant for alien species establishment in forests. Species that established successfully in disturbed forest had a greater planting effort than unsuccessful species, and species found in intact forest were planted nearer to forest edges. The apparently low invasibility of tropical rain forests in general could result from low propagule pressure of alien plant species with suitable traits, which would facilitate invasion (Fine, 2002; Denslow \& DeWalt, 2008; Martin et al., 2009). The results from this study suggest that tropical forests may only be permeable to colonization by alien plant species when propagule sources are in close proximity, as observed for other natural and semi natural habitats (Rouget \& Richardson, 2003; Edward et al., 2009). The situation in ABG may be replicated in many other botanic gardens in the tropics and indicates such institutions as potentially high risk sources of invasive plants historically (Hulme, 2011c).

Previous studies have found clear differences in leaf traits between alien and native plant species (Baruch \& Goldstein, 1999; Dietz et al., 2004; Leishman et al., 2007; Penuelas et al., 2010) and between invasive and non invasive aliens (Grotkopp et al., 2002; Hamilton et al., 2005; Grotkopp \& Rejmánek, 2007). In contrast, we found no relationship between successful establishment in either disturbed or intact forest and a leaf traits spectrum in our study. Differences in K concentration were not significant between species establishing and not establishing in intact forest when considered alone, but intact forest establishment was best explained by distance of planta tions to forest edges and foliar $\mathrm{K}$ concentration together. However, foliar $\mathrm{K}$ was not significantly associated with canopy cover in quadrats where species were establishing, which would be expected if foliar $\mathrm{K}$ was important for establishment in forest understoreys. Further work is needed to understand if foliar $\mathrm{K}$ concentration plays a greater role in plant establishment in the dynamic light conditions of intact forest understoreys com pared with disturbed forest (Santiago \& Wright, 2007).

In addition, we found that invasion risk according to the WRA protocol was also unrelated to the leaf traits spectrum or to any individual leaf traits. Species with a higher likelihood of invasion did not occupy a different part of the leaf traits spectrum compared with species with lower invasion risk. This indicates that leaf traits per se may be of little value as a 

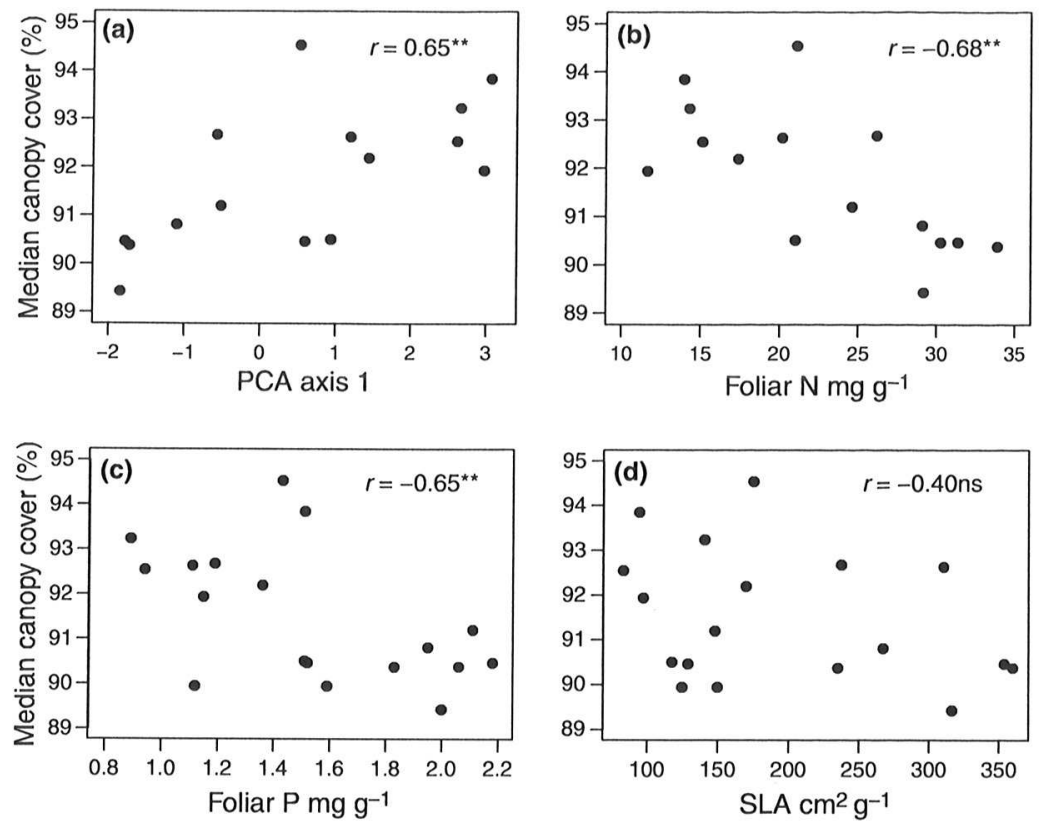

Figure 3 Correlations between median canopy cover (\%) in forest quadrats occupied by seedlings and saplings of 15 species, and (a) the principal components analysis leaf trait axis, (b) foliar $\mathrm{N}$ concentration, (c) Foliar P concentration and (d) SLA. $R=$ correlation coefficient; ${ }^{* *}$ Significant correlation, $P \leq 0.01$; $\mathrm{ns}=$ correlation not significant.

predictive tool in WRA. Instead, the majority of high risk species were bird or primate dispersed and had smaller seeds. The WRA process does contain questions specific to dispersal and seed ecology, but only positive weightings are given for endozoochory of any animal (not just birds or primates) and also for wind and water dispersal modes, and only \pm 1 point depends on species seed output, thus making bias in WRA scoring according to dispersal and seed size unlikely. However, an important factor contributing to the final WRA score is whether or not species are known to be invasive or weeds elsewhere (Rejmánek et al., 2005). This result therefore simply reflects that the majority (12 of 17) of bird or primate dispersed species and species with smaller seeds in this study are invasive in other parts of their introduced range (Dawson et al., 2009b). In this study, a number of species found in disturbed $(n=7)$ and intact forests $(n=4)$ are not predicted to be of high risk by the WRA system, whilst 12 species judged to be of high risk are not found in disturbed $(n=3)$ or intact $(n=9)$ forest. The lack of complete congruence between WRA invasion risk as establishment success in intact forest reflects that invaders of forest may have different attributes to invaders of more open habitats. Hence, the WRA may be better placed to identify such 'open habitat' species (Dawson et al., 2009b), which was the original purpose of the devised protocol (Pheloung et al., 1999). Forests are complex communities with multiple habitat types within them; we suggest that a suite of traits (instead of one) are thus likely to characterize successful forest invaders, with propagule pressure being of primary importance.
Propagule pressure was evidently important for the success ful establishment of species in disturbed forest, but species with an earlier introduction date were not more likely to establish in either forest type than species planted more recently. Whilst the majority of species in this study are long lived and woody, most (28 species) were planted within a 10 year period from 1902 to 1912. Perceived lag phases before naturalization and spread may be shorter for tropical than for temperate species owing to year round favourable conditions for growth and/or a greater potential for establishment and spread into semi natural and natural vegetation (Daehler, 2009). The most recently planted species have also been present for 75 years, giving a narrow range of residence times that has been sufficient for all species to reach reproductive maturity and recruit new adults into the population (i.e. to naturalize). These factors may explain why residence time was unimpor tant in our study in contrast to others.

Dispersal by animals and birds is often considered an important attribute of successful invaders, particularly of those that infiltrate less disturbed ecosystems (Buckley et al., 2006; Milton et al., 2007). Species known to be dispersed by birds and primates in this study were only marginally more likely to be found establishing in disturbed forest. Some notable exceptions include Cedrela odorata and Spathodea campanu lata, which are two wind dispersed tree species that were found in quadrats in both disturbed and intact forests. Our binary dispersal variable combines a heterogeneous group of species that are not dispersed by birds or primates into one category, which includes species dispersed by wind and other 
mechanisms. However, our results do suggest that bird/ primate dispersed species appear to have a slight advantage in forest establishment over all other dispersal modes repre sented in our sample. Our study may have captured the bulk of shorter distance dispersal into forests surrounding $A B G$, but longer distance dispersal events would have been missed, such that the extent of forest establishment presented here for species dispersed by birds and primates or wind in particular may be rather conservative. Furthermore, the greater the number of plantations and thus seed supply, the higher the likelihood of detecting long distance dispersal events. A number of species introduced to ABG have become widespread through bird dispersal in the East Usambaras, including C. hirta, L. camara and M. eminii (Cordeiro et al., 2004), but were excluded from our initial analyses owing to the absence of records of introduction history. In the case of $M$. eminii, dispersal by silvery cheeked hornbills (Ceratogymna brevis) may transport seeds over tens of kilometres in the East Usambaras (Cordeiro et al., 2004).

Propagule pressure was of greater significance than dispersal for seedling establishment in forest, and this result emphasizes the importance of accounting for propagule pressure in comparative studies of invasions (Lockwood et al., 2005; Edward et al., 2009). Thus, to what extent are traits important in forest colonization? We found that among 15 species establishing in forest areas, the PCA axis representing the leaf trait spectrum was correlated with median canopy cover of occupied forest quadrats. This indicates that, given sufficient seed rain into forest habitats, seedlings and saplings of alien species will survive and become established in the available habitats that best reflect their light requirements for growth. Yet, the main limitation to establishment was propagule pressure, and species occurrence seems to represent a 'spill over' of propagules dispersed from nearby plantations; hence, the principle barrier to successful establishment was the distance from a propagule source.

Whilst it seems unlikely that leaf traits relating to life history strategy are of primary importance in distinguishing between invasive and non invasive species, they may act in concert with habitat characteristics to filter out and exclude maladapted species that might otherwise benefit from high propagule pressure. A trade off between growth and survival in plants is likely to determine different optima for the performance of fast growing and slow growing species along natural light gradients (Wright et al., 2004; Poorter \& Bongers, 2006). An introduced species pool that contains species scattered along the leaf economics spectrum, with a corresponding diversity of growth and resource allocation strategies, should result in invasion of a wide range of habitats by species with varied suites of traits, and which are likely to resemble traits possessed by cooccurring native species. Trait similarity between native and alien species depending on habitat has recently been demonstrated for alien plant species invading different habitats in Australia (Leishman et al., 2010) and also partially in Argentina (Tecco et al., 2010). In contrast, invasive alien species with 'fast' growth and resource allocation strategies in Hawaii were able to exploit and invade biogeochemical niches left vacant by 'slower' native species (Penuelas et al., 2010), and aliens naturalizing in Mediterranean islands tended to be more effective at competing for non limiting resources than native species (Lambdon et al., 2008b). These studies suggest that being different from native plant communities can be as successful for aliens as 'fitting in' when novel and unexploited habitats coincide with high propagule pressure of alien species with suitable traits.

To conclude, we found little evidence of a relationship between leaf traits and establishment of alien plant species in tropical forest, and no differences in leaf traits between species judged to be of high and low invasion risk according to the WRA protocol. We suggest that leaf traits are not always primary determinants of invasion success and that their often perceived role is very likely to be habitat dependent and secondary to propagule pressure. Successful invasion of natural areas may depend upon high propagule pressure of species with certain traits coinciding with the availability of corre spondingly suitable habitats.

\section{ACKNOWLEDGEMENTS}

This work is part of the Darwin Initiative project 'Combating alien invasive plants threatening the East Usambara mountains in Tanzania' (162/13/033), and authors are grateful for financial support from Defra. The work was additional supported by A NERC Postgraduate Studentship (W.D.). The authors also thank the staff of the Amani Nature Reserve, especially the late Mr. Corodius T. Sawe, and the Tropical Biological Association, especially Rosie Trevelyan, for logistical support. Thanks to Iddy Rajabu (botanist, Tanzanian Forestry Research Institute) and Mr. Abduel B. Kajiru, for fieldwork assistance. Thanks also to Caroline LeCroart and Antonin LeCampion for conducting foliar nutrient analyses.

\section{REFERENCES}

Allen, S.E., Grimshaw, H.M., Parkinson, J.A. \& Quarmby, C. (1989) Chemical analysis of ecological material. Blackwell Scientific Publications Ltd., Oxford.

Baruch, Z. \& Goldstein, G. (1999) Leaf construction cost, nutrient concentration, and net $\mathrm{CO}_{2}$ assimilation of native and invasive species in Hawai'i. Oecologia, 121, 183192.

Buckley, Y., Anderson, A., Catterall, C., Corlett, R., Engel, T., Gosper, C., Nathan, R., Richardson, D., Setter, M., Spiegel, O., Vivian Smith, G., Voigt, F., Weir, J. \& Westcott, D. (2006) Management of plant invasions mediated by frugi vore interactions. Jounal of Applied Ecology, 43, 848857.

Cordeiro, N.J., Patrick, D.A.G., Munisi, B. \& Gupta, V. (2004) Role of dispersal in the invasion of an exotic tree in an East African submontane forest. Journal of Tropical Ecology, 20, 449457.

Cornelissen, J.H.C., Lavorel, S., Garnier, E., Diaz, S., Buch mann, N., Gurvich, D.E., Reich, P.B., ter Steege, H., Morgan, H.D., van der Heijden, M.G.A., Pausas, J.G. \& Poorter, H. (2003) A handbook of protocols for standardised and easy 
measurement of plant functional traits worldwide. Aus tralian Journal of Botany, 51, 335380.

Daehler, C.C. (2009) Short lag times for invasive tropical plants: evidence from experimental plantings in Hawai'i. PLoS ONE, 4, e4462.

Dawson, W., Mndolwa, A.S., Burslem, D.F.R.P. \& Hulme, P.E (2008) Assessing the risks of plant invasions arising from collections in tropical botanical gardens. Biodiversity and Conservation, 17, 19791995.

Dawson, W., Burslem, D.F.R.P. \& Hulme, P.E. (2009a) Factors explaining alien plant invasion success in a tropical ecosys tem differ at each stage of invasion. Journal of Ecology, 97, 657665.

Dawson, W., Burslem, D.F.R.P. \& Hulme, P.E. (2009b) The suitability of weed risk assessment as a conservation tool to identify invasive plant threats in East African rainforests. Biological Conservation, 142, 10181024.

Denslow, J.S. \& DeWalt, S.J. (2008) Exotic plant invasions in tropical forests: patterns and hypotheses. Tropical forest community ecology (ed. by W. Carson and S. Schnitzer), pp. 409 426. Blackwell Publishing Ltd., Oxford.

Dietz, H., Wirth, L.R. \& Buschmann, H. (2004) Variation in herbivore damage to invasive and native woody plant species in open forest vegetation on Mahe, Seychelles. Biological Invasions, 6, 511521.

Edward, E., Munishi, P.K.T. \& Hulme, P.E. (2009) Relative roles of disturbance and propagule pressure on the invasion of humid tropical forest by Cordia alliodora (Boraginaceae) in Tanzania. Biotropica, 41, 171178.

Fine, P.V.A. (2002) The invasibility of tropical forests by exotic plants. Journal of Tropical Ecology, 18, 687705.

Gordon, D.R., Onderdonk, D.A., Fox, A.M. \& Stocker, R.L. (2008) Consistent accuracy of the Australian weed risk assessment system across varied geographies. Diversity and Distributions, 14, 234242.

Gosper, C.R. \& Vivian Smith, G. (2009) The role of fruit traits of bird dispersed plant in invasiveness and weed risk assessment. Diversity and Distributions, 15, 10371046.

Grotkopp, E. \& Rejmánek, M. (2007) High seedling relative growth rate and specific leaf area are traits of inva sive species: phylogenetically independent contrasts of woody angiosperms. American Journal of Botany, 94, 526 532.

Grotkopp, E., Rejmánek, M. \& Rost, T.L. (2002) Toward a causal explanation of plant invasiveness: seedling growth and life history strategies of 29 pine (Pinus) species. American Naturalist, 159, 396419.

Hamilton, M.A., Murray, B.R., Cadotte, M.W., Hose, G.C., Baker, A.C., Harris, C.J. \& Licari, D. (2005) Life history correlates of plant invasiveness at regional and continental scales. Ecology Letters, 8, 10661074.

Hulme, P.E. (2011a) Contrasting impacts of climate driven flowering phenology on changes in alien and native plant species distributions. New Phytologist, 189, 272281.

Hulme, P.E. (2011b) Biosecurity: the changing face of invasion biology. Fifty years of invasion ecology the legacy of Charles
Elton (ed. by D.M. Richardson), pp. 301 314. Wiley Black well, Oxford.

Hulme, P.E. (2011c) Addressing the threat to biodiversity from botanic gardens. Trends in Ecology and Evolution, 26, 168174.

Krivanek, M., Pyšek, P. \& Jarosik, V. (2006) Planting history and propagule pressure as predictors of invasion by woody species in a temperate region. Conservation Biology, 20, 14871498.

Lambdon, P.W., Lloret, F. \& Hulme, P.E. (2008a) How do introduction characteristics influence the invasion success of Mediterranean alien plants? Perspectives in Plant Ecology, Evolution and Systematics, 10, 143159.

Lambdon, P.W., Lloret, F. \& Hulme, P.E. (2008b) Do alien plants on Mediterranean islands tend to invade different niches from native species? Biological Invasions, 10, 703716.

Leishman, M.R., Haslehurst, T., Ares, A. \& Baruch, Z. (2007) Leaf trait relationships of native and invasive plants: com munity and global scale comparisons. New Phytologist, 176, 635643.

Leishman, M.R., Thomson, V.P. \& Cooke, J. (2010) Native and exotic invasive plants have fundamentally similar carbon capture strategies. Journal of Ecology, 98, 2842.

Lemmon, P.E. (1956) A spherical densiometer for estimating forest overstory density. Forest Science, 2, 314320.

Lloret, F., Médail, F., Brundu, G., Camarda, I., Moragues, E., Rita, J., Lambdon, P. \& Hulme, P.E. (2005) Species attributes and invasion success by alien plants in Mediterranean islands. Journal of Ecology, 93, 512520.

Lockwood, J.L., Cassey, P. \& Blackburn, T. (2005) The role of propagule pressure in explaining species invasions. Trends in Ecology and Evolution, 20, 223228.

Martin, P.H., Canham, C.D. \& Marks, P.L. (2009) Why forests appear resistant to exotic plant invasions: intentional intro duction, stand dynamics, and the role of shade tolerance. Frontiers in Ecology and the Environment, 7, 142149.

Milton, S.J., Wilson, J.R.U., Richardson, D.M., Seymour, C.L., Dean, W.R.J., Iponga, D.M. \& Procheş, S. (2007) Invasive alien plants infiltrate bird mediated shrub nucleation pro cesses in arid savanna. Journal of Ecology, 95, 648661.

Penuelas, J., Sardans, J., Llusia, J., Owen, S.M., Carnicer, J., Giambelluca, T.W., Rezende, E.L., Waite, M. \& Niinemets, U. (2010) Faster returns on 'leaf economics' and different biogeochemical niche in invasive compared with native plant species. Global Change Biology, 16, 21712185.

Pheloung, P.C., Williams, P.A. \& Halloy, S.R. (1999) A weed risk assessment model for use as a biosecurity tool evaluating plant introductions. Journal of Environmental Management, 57, 239251.

Poorter, L. \& Bongers, F. (2006) Leaf traits are good predictors of plant performance across 53 rain forest species. Ecology, 87, 17331743.

Pyšek, P. \& Richardson, D.M. (2007) Traits associated with invasiveness in alien plants: where do we stand? Biological invasions, ecological studies 193 (ed. by W. Nentwig), pp. 97 126. Springer Verlag, Berlin \& Heidelberg. 
R Development Core Team (2009) R: a language and envi ronment for statistical computing. R Foundation for Statistical Computing, Vienna, Austria. ISBN 390005107 0. Available at: http://www.R project.org.

Rasband, W.S. (2007) ImageJ, U.S. National Institutes of Health, Bethesda, MD, U.S.A.. Available at: http://rsb.info. nih.gov/ij/ (downloaded 2007).

Reich, P.B., Ellsworth, D.S. \& Walters, M.B. (1998) Leaf structure (specific leaf area) modulates photosynthesis nitrogen relations: evidence from within and across species and functional groups. Functional Ecology, 12, 948958.

Rejmánek, M. \& Richardson, D.M. (1996) What attributes make some plant species more invasive? Ecology, 77, 1655 1661.

Rejmánek, M., Richardson, D.M., Higgins, S.I., Pitcairn, M. \& Grotkopp, E. (2005) Ecology of invasive plants: state of the art. Invasive alien species: a new synthesis (ed. by H.A. Moody, J.A. McNeely, L. Neville, P.J. Schei and J. Waage), pp. 104 162. Island Press, Washington, DC.

Richardson, D.M. \& Pyšek, P. (2006) Plant invasions: merging the concepts of species invasiveness and community invasi bility. Progress in Physical Geography, 30, 409431.

Rouget, M. \& Richardson, D.M. (2003) Inferring process from pattern in plant invasion: a semimechanistic model incor porating propagule pressure and environmental factors. American Naturalist, 162, 713724.

Royal Botanic Gardens, Kew (2008) Electronic plant informa tion centre. Available at: http://epic.kew.org/epic/ (accessed 2006 2008)

Santiago, L.S. \& Wright, S.J. (2007) Leaf functional traits of tropical forest plants in relation to growth form. Functional Ecology, 21, 1927.

Simberloff, D. (2009) The role of propagule pressure in bio logical invasions. Annual Review of Ecology, Evolution and Systematics, 40, 81102.

Tecco, P.A., Diaz, S., Cabido, M. \& Urcelay, C. (2010) Func tional traits of alien plants across contrasting climatic and land use regimes: do aliens join the locals or try harder than them? Journal of Ecology, 98, 1727.

Williamson, M., Dehnen Schmutz, K., Kuhn, I., Hill, M., Klotz, S., Milbau, A., Stout, S. \& Pyšek, P. (2009) The dis tribution of range sizes of native and alien plants in four European countries and the effects of residence time. Diversity and Distributions, 15, 158166.

Wilson, J.R.U., Richardson, D.M., Rouget, M., Proches, S., Amis, M.A., Henderson, L. \& Thuiller, W. (2007) Residence time and potential range: crucial considerations in modelling plant invasions. Diversity and Distributions, 13, 1122.

Wright, I.J., Reich, P.B., Westoby, M. et al. (2004) The worldwide leaf economics spectrum. Nature, 428, 821827.

\section{SUPPORTING INFORMATION}

Additional Supporting Information may be found in the online version of this article:

Table S1 Leaf traits, seed weights, dispersal and propagule pressure data for species used in the study.

Table S2 Summaries of full models analysing forest establish ment success and invasion risk, including individuals leaf traits with other explanatory variables.

As a service to our authors and readers, this journal provides supporting information supplied by the authors. Such mate rials are peer reviewed and may be re organized for online delivery, but are not copy edited or typeset. Technical support issues arising from supporting information (other than missing files) should be addressed to the authors.

\section{BIOSKETCH}

Wayne Dawson is a plant ecologist working at the University of Konstanz in Germany. His main research focus since his $\mathrm{PhD}$ thesis has been the ecology of plant invasions both in tropical Africa and in Europe. He is currently also researching the causes of plant rarity and the importance of aboveground belowground linkages in influencing plant performance.

Editor: John Wilson 